\title{
TRADUÇÃO DE MÚSICA NO ENSINO DE ALEMÃO COMO LÍNGUA ESTRANGEIRA $^{1}$
}

Translation of music in german teaching as a foreign language

\author{
Ulrike PLEß - DAAD \\ Tradução de Luiz ABDALA JUNIOR - UFPR
}

RESUMO: No artigo Tradução de música no ensino de alemão como língua estrangeira discute-se a relevância da tradução de músicas na aula de alemão como língua estrangeira. Nesse contexto, faz-se uma sugestão didática para diferentes níveis de aprendizado. $\mathrm{O}$ objetivo é que os estudantes possam vislumbrar o mundo estrangeiro e entrar em contato com a sua cultura. Ao realizar traduções de letras de música, lidando intensivamente com a língua estrangeira, os estudantes podem aprender tanto através dos apelos afetivos que a música proporciona, quanto com os elementos linguísticos da letra.

PALAVRAS-CHAVE: tradução; música; alemão como língua estrangeira

ABSTRACT: The article Übersetzen von Liedern im DaF-Unterricht discusses how translating songs is relevant to German as a foreign language. In this context, a didactic proposal for different language levels is made. The goal is for the participants to gain an insight into the foreign world and its culture. By dealing with the translation of the lyrics intensively they are to learn both from the emotional effect that is caused by the music, as well as from the linguistic elements of the song.

KEYWORDS: translation; songs; german as a foreign language

\section{INTRODUÇÃO}

Tradução e ensino de línguas estrangeiras mantêm desde sempre uma relação delicada. Um não existe sem o outro e, apesar disso, a tradução, após o método da Gramática-Tradução, há anos foi banida do ensino de língua alemã (ver HAß 2010, p.151). Já há algum tempo existem abordagens bem sucedidas que reintegram a tradução dentro da sala de aula, que também aparece incluída no Quadro Europeu Comum de Referência para as Línguas (QCER) (ver TRIM e. al, 2001, p.89).

Não é novidade que a aprendizagem de uma língua estrangeira destacada do seu contexto cultural é difícil. Por isso, destaca-se cada vez mais a importância da inclusão

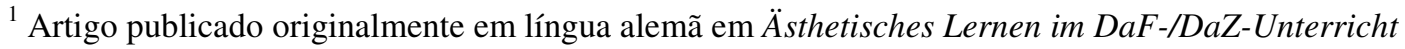
Literatur - Theater - Bildende Kunst - Musik - Film. ISBN: 978-3-86395-183-2. Disponível em: << https://univerlag.uni-goettingen.de/bitstream/handle/3/isbn-978-3-86395-183-2/MatDaF93_978-3-86395183-2.pdf? sequence=3\&isAllowed=y $>>$
} 
de diferentes formas artísticas na apresentação de aspectos culturais em sala de aula. A estética como um lugar de encontro na sala de aula alcança a sensibilidade dos estudantes. $\mathrm{O}$ aprendizado desde o viés estético ativa simultaneamente diferentes sentidos, proporcionando uma aproximação emocional e uma percepção holística da língua de maneira muito mais ampla que o aprendizado racional. A elemento estético oferece à maioria dos estudantes a possibilidade de alcançar uma relação afetiva com suas realidades e as posicionarem em relação à realidade do mundo. Deste modo, eles vivenciam a sala de aula como um lugar de encontro cultural totalmente novo e refletem a experiência afetivamente, unida aos seus conhecimentos anteriores.

Isto é, os estudantes estabelecem novas conexões. A música é um exemplo do uso do elemento estético na aprendizagem através de um meio cultural autêntico. Pode ser utilizada de diferentes maneiras na aula de alemão e atende, dependendo da tarefa, várias ou até mesmo todas as quatro habilidades comunicativas. (ver WICKE ROTTMAN, 2013, p.4)

No presente artigo serão analisadas as possibilidades e impossibilidades da tradução de música no ensino de alemão como língua estrangeira (ver KEIM, 2003, p. 388), sobretudo através do caso de falantes nativos do espanhol que estudam alemão no CUCSH (Centro Universitário de Ciências Sociais e Humanidades) da Universidade de Guadalajara, no México. Pretendemos apontar as vantagens, assim como as dificuldades, dessa tarefa, apresentando-a a partir de diferentes exemplos. Para isso, são utilizadas músicas que condizem bem com os diferentes níveis de língua estudados.

\section{MÚSICA NA AULA DE ALEMÃo}

A música tem um papel importante em diferentes culturas. É um fenômeno social e, ambas, tanto a música quanto a sociedade, se relacionam mutuamente. Quase todo indivíduo se sente motivado pela música.

A música é, tradicionalmente, uma forma curta ou épica que representa a expressão mais original dos sentimentos. Está ancorada na sociedade e pode ser utilizada para identificar diferentes grupos socioculturais. Ela é um importante e autêntico difusor de cultura que dá a conhecer os atuais movimentos, pensamentos e sentimentos da sociedade.

Afirma o neurologista Eckart Altenmüller: "A música é o maior estímulo à reestruturação neurológica que nós conhecemos" (ALTENMÜLLER, 2003, p. 68). O 
professor deve fazer uso dessa afirmação em sala de aula. Músicas são marcadas por sensações afetivas e podem ter um efeito relaxante e estimulante nos ouvintes e, além disso, são um ótimo meio de romper com a rotina das aulas. Elas podem aumentar a motivação dos alunos e também contribuir na mediação de temas culturais. Com a música, é possível praticar as quatro habilidades comunicativas, introduzir vocabulário ou praticar e consolidar conhecimentos gramaticais. O uso da música, como vemos, pode ser muito vantajoso. Com tantas possibilidades de exploração, o professor pode escolher uma delas.

\section{TRADUÇÃO NA AULA DE ALEMÃO COMO LÍNGUA ESTRANGEIRA}

Embora a tradução no ensino de línguas estrangeiras tenha permanecido à margem durante muito tempo, existem diferentes argumentos que falam ao seu favor. Por exemplo, sabe-se que o monolinguismo não é possível em sala de aula, pois a língua materna está sempre na cabeça dos estudantes.

O estudante não traz apenas a sua língua materna à aula, mas também outras, de forma que línguas estrangeiras já aprendidas estão simultaneamente presentes na sua cabeça e geram, durante o aprendizado, um grande potencial informativo e um material de apoio que não deve ser negligenciado em sala de aula. (DE CARVALHO NETO, 2005. p. 34)

Ao utilizar-se a tradução, comparam-se os elementos aprendidos àqueles da língua materna assim como aos de outras línguas estrangeiras aprendidas. Além disso, a tradução é um recurso efetivo para a conscientização dos erros. Os professores devem levar em conta, no entanto, que os exercícios de tradução devem ser utilizados, principalmente, para treinar a compreensão do texto e precisam corresponder aos conteúdos gerais da aula. Além disso, o grau de dificuldade e o formato dos exercícios devem estar adequados aos alunos (KÖNIGS, 2010, p.98)

Ulrike Draesner afirma que "a tradução é o jeito mais profundo que conheço de se ler um texto". (DRAESNER, 2008). Esse tipo de trabalho de tradução de texto ajuda os alunos em sua compreensão e, em muitos casos, a perceber que o entenderam muito mais do que imaginavam quando apenas o haviam lido cuidadosamente.

A tradução - e a tarefa de interpretar - já foram incluídas há algum tempo no QCER sob o termo genérico de mediadoras de linguagem. São consideradas atividades mediadoras de linguagem aquelas que: 
Não se tratam de o falante da língua trazer suas intenções à tona, mas que possam ser um medium entre interlocutores que não conseguem se entender, pois não falam a mesma língua (este é o caso mais comum, porém não o único). São consideradas atividades mediadoras de linguagem a interpretação e a tradução, assim como o resumo e a paráfrase de um texto na mesma língua, caso aquele a quem o texto é dirigido não consiga entendê-lo. (TRIM et. al, 2001.p.89)

O QCER apresenta uma diferenciação entre mediação de linguagem escrita e oral. Não existe uma escala de avaliação para ambas. Sob mediação de linguagem escrita o QCER toma, entre outras, a tradução literária. A tradução de músicas, enquanto gênero literário, no entanto, não está presente.

Podem-se realizar diferentes tarefas de tradução em aulas de alemão. Os alunos podem traduzir, por exemplo, suas próprias frases, de modo a atentarem aos seus erros. Podem-se traduzir textos genéricos para a introdução de diferentes temáticas. Textos com aspectos regionais podem ser traduzidos com a finalidade da mediação de características culturais, assim como textos técnicos, como, por exemplo, sobre a temática Erfindung (Invenção).

\section{TRADUÇÃO DE MÚSICA}

Outro trabalho possível é a tradução de música. O professor tem duas possibilidades: escolher uma música do seu gosto, relacionada com o tema da aula a ser dada. Essa possibilidade cabe, sobretudo, nos níveis iniciais, de modo a conduzir o aprendizado dos estudantes. Outra possibilidade é o professor pedir aos alunos que escolham uma música. Essa deve ser apresentada com o nome do grupo, título, temática, assim como a justificativa dela ter sido escolhida. Se necessário, o professor deve intervir para garantir que a música é adequada para subsequente tradução. Os estudantes recebem então a seguinte tarefa: Um amigo mexicano escutou uma música alemã, da qual gostou muito. Porém, ele não entende alemão e sabe que você estuda a língua. Ele te pede para ajudá-lo com a tradução da música. Traduza a letra de maneira que seu amigo não tenha problemas para entendê-la. Adicione, se necessário, esclarecimentos a respeito do processo. Os estudantes traduzem a letra da música como tarefa de casa ou durante a aula. Neste último caso, o acesso à internet deve ser fornecido. É necessário que os estudantes tenham tempo suficiente, de modo que possam realizar pesquisas mais aprofundadas, se for preciso. A tarefa corresponde à “autêntica simulação de situações de mediação de linguagem” (KÖNIGS, 2010, p.98). É 
uma tarefa muito realista e deve ser resolvida de modo satisfatório pelos estudantes, isto é, com acesso à internet, dicionários, consulta aos colegas ou amigos, falantes nativos, etc. Deve-se também sugerir aos estudantes não utilizar o Google Tradutor, ou se o utilizarem, que o façam com cautela, pois tal ferramenta é uma máquina e não um serviço profissional, estando traduções geradas dessa forma bastante propensas a erros. ${ }^{2}$

Minhas experiências com a realização dessas tarefas estão principalmente relacionadas aos níveis iniciantes A1 e A2. Abaixo apresento exemplos de diferentes músicas traduzidas pelos alunos. As traduções variam de resultados satisfatórios e ruins até exemplos negativos, isto é, músicas que não são adequadas para a tarefa ou para o nível.

A primeira música a ser aqui apresentada é Mach die Augen zu do Die Ärzte. A música foi predeterminada pelo professor com o objetivo de apresentar o tema gramatical "imperativo" em uma turma de nível A1. Com base em um trecho da música, são apontadas algumas questões problemáticas: Mach die Augen zu und küss mich/und dann sag, dass du mich liebst/ich weiß genau, es ist nicht wahr/doch ich spüre keinen Unterschied - wenn du dich mir hingibst...* Mais complicado aos estudantes são o verbo separável "zumachen”, que eles ainda não conhecem, e a expressão idiomática "sich jmdm. hingeben". No entanto, durante a tradução, tais dificuldades foram superadas sem maiores problemas e a atividade foi realizada com sucesso. Os estudantes entenderam o imperativo logo à primeira vista e gostaram da música e da letra. A música correspondeu ao gosto pessoal de muitos estudantes e os incentivou a ouvir mais composições do grupo. Também contribuiu o fato de a letra ser cantada de uma forma clara e compreensível.

Outra música recomendada para esse nível e que foi traduzida é Du Hast ${ }^{3}$, do grupo Rammstein. Essa música foi escolhida pelos próprios estudantes, pois, por um lado, o grupo é bastante conhecido no México e ouvido pelos alunos, e, por outro, para o esclarecimento de mudanças de significados advindas de pequenas alterações nas

\footnotetext{
${ }^{2}$ Como recomendação existem os dicionários online Pons, Langenscheidt ou Duden, assim como enciclopédias como a Wikipédia.

${ }^{3}$ Rammstein: Sehnsucht. Temple Studios 1997.

*Marcado em asterisco, estão as traduções para o português das letras das músicas aqui citadas, realizadas pelo próprio tradutor do artigo para fins didáticos de compreensão das versões em alemão e espanhol: Feche os olhos e me beije/E diga que me ama/Eu sei bem que não é verdade/Mas eu não sinto qualquer diferença/Quando você se entrega pra mim

**Você/Você tem/Você me odeia/Você me odeia/Você me perguntou/Você me perguntou/Você me perguntou e eu não disse nada/Você quer que a morte os separe/ser fiel a ela todos os dias?
} 
palavras. "Du $-d u$ hast $-d u$ hasst mich $-d u$ hasst mich $-d u$ hast mich gefragt $-d u$ hast mich gefragt - du hast mich gefragt und ich hab nichts gesagt! - Willst du bis der Tod euch scheidet - treu ihr sein für alle Tage - Nein, nein”** (RAMMSTEIN, 2013). A principal dificuldade da letra está na articulação parecida entre " $d u$ hast" e " $d u$ hasst", assim como no entendimento da frase "Willst du bis der Tod euch scheidet, treu ihr sein für alle Tage?". No entanto, os estudantes superaram os obstáculos de forma independente e sem problemas. As palavras soltas são relativamente fáceis de compreender. O refrão, ao contrário, não tanto.

No nível A2 foi utilizada a outra variante dessa atividade, na qual os estudantes podem escolher a música de sua preferência.

Como primeiro exemplo cabe a música Das Zelt de Jeans Team, que uma estudante escolheu e traduziu. Como é possível ver na correção (em itálico) da tarefa apresentada, a tradução não foi problemática. Mesmo que a letra apresente um ou outro desafio ao tradutor, este é um exemplo ideal para o nível A2, pois no geral não há grandes problemas de compreensão para os estudantes. Além disso, a música é cantada de tal forma que boa parte do texto já pode ser entendido logo ao ouvi-la.

Tradução da música Das Zelt ${ }^{4}$ de Jeans Team:

\begin{tabular}{|l|l|}
\hline Das Zelt - Jeans Team & La carpa - Jeans Team \\
Mach dich auf (aufmachen nach= \\
abrirse camino a, ponerse en camino & Ponte en camino \\
hacia) & En el mundo \\
In die Welt & En otro país \\
In ein anderes Land & En donde te guste \\
Wo es dir gefällt & Hasta el borde \\
Bis zum Rand(borde) & Y sobre el mar \\
und übers Meer & Te detiene \\
Dich hält (hälten=retener) & Aquí ya nada \\
hier nichts mehr & \\
Kein Gott & \\
Kein Staat & Sin ${ }^{5}$ dios \\
Keine Arbeit & Sin estado \\
Kein Geld (x2) & Sin trabajo \\
Aus dem Haufen (montón) & Sin dinero (x2) \\
\hline
\end{tabular}

\footnotetext{
${ }^{4}$ Jeans Team: Das Zelt. Louisville Records 2006.

${ }^{5}$ Os erros de tradução estão sempre marcados em itálico.
} 


\begin{tabular}{|l|l|}
\hline Dieser Stadt & De esta ciudad \\
Musst du raus(fuera) & Debes tú salir \\
Und du wirst sehen & Y tú verás \\
Du wirst dich verändern (cambiar) & Tú cambiaras \\
In all diesen Ländern & En todas estos países \\
Kein Gott & Sin dios \\
Kein Staat & Sin estado \\
Keine Arbeit & Sin trabajo \\
Kein Geld & Sin dinero \\
Mein Zuhause (hogar) & Mi casa \\
Ist die Welt & Es el mundo \\
Mein Zuhause & Mi casa \\
Ist die Welt & Es el mundo \\
Das Himmelszelt (firmamento, cielo) & El firmamento \\
Ist dein Dach & Es tu techo \\
Mit all den Lichtern(luces) & Con todas las luces \\
Die dich leiten(guiar) & Que te guiarán \\
Von den Sternen (Stern= estrella) & De las estrellas \\
Die dich begleiten(acompañar) & Que te acompañará \\
Kannst du lernen & Puedes tú aprender \\
Klar zusehen (a ver) & A ver claramente \\
Kein Gott & Sin dios \\
Kein Staat & Sin estado \\
Keine Arbeit & Sin trabajo \\
Kein Geld & Sin dinero \\
Mein Zuhause & Mi casa \\
Ist die Welt & Es el mundo \\
Mein Zuhause & Mi casa \\
Ist die Welt (x3) & Es el mundo (x3)*** \\
\hline
\end{tabular}

É lugar comum a escolha dos estudantes recair em 99 Luftballons $^{6}$, de Nena. Isso se deve à fama relativamente grande da música em todo o mundo. Trata-se de um texto mais sofisticado, que traz diferentes problemas ao longo da sua tradução.

Tradução da música 99 Luftballons de Nena

\footnotetext{
${ }^{6}$ Nena: 99 Luftballons. Epic Records, 1984

***Ponha-se a caminho/No mundo/ Em um outro país/Que você goste/Até a margem/E sobre o mar/Pare/Não há nada aqui/Não há Deus/Não há Estado/Não há trabalho/Não há dinheiro/Das pilhas/Dessa cidade/Você deve sair/E você verá/Você irá mudar/Em todos esses países/Não há Deus/Não há Estado/Não há trabalho/Não há dinheiro/Meu lar/É o mundo/Meu céu/É o seu telhado/Com todas as luzes/Que te guiam/Das estrelas/Que te acompanham/Você pode aprender/A ver claramente//Não há Deus/Não há Estado/Não há trabalho/Não há dinheiro/Meu lar/É o mundo/Meu lar/É o mundo
} 
Hast du etwas Zeit für mich?

Dann singe ich ein Lied für dich Von 99 Luftballons

Auf ihrem Weg zum Horizont

Denkst du vielleicht g'rad an mich

Dann singe ich ein Lied für dich

Von 99 Luftballons

Und dass so was von so was kommt

99 Luftballons

Auf ihrem Weg zum Horizont

Hielt man für Ufos aus dem All

Darum schickte ein General

'ne Fliegerstaffel hinterher

Alarm zu geben, wenn es so wär

Dabei war'n da am Horizont

Nur 99 Luftballons

\section{Düsenjäger}

Jeder war ein großer Krieger

Hielten sich für Captain Kirk

Das gab ein großes Feuerwerk

Die Nachbarn haben nichts gerafft

Und fühlten sich gleich angemacht

Dabei schoss man am Horizont

Auf 99 Luftballons

99 Kriegsminister -

Streichholz und Benzinkanister -

Hielten sich für schlaue Leute

Witterten schon fette Beute

Riefen Krieg und wollten Macht

Mann, wer hätte das gedacht

Dass es einmal soweit kommt

Wegen 99 Luftballons
¿Tienes algo de tiempo para mí?

Entonces canto una canción para ti acerca de 99 globos

En su camino al horizonte

¿Piensas tú tal vez en mí?

Entonces canto una canción para ti

Acerca de 99 globos

Y ese algo viene de algo

(Ella soltó los globos dedicados para él)

99 globos

En su camino al horizonte

Los considera uno OVNIs del espacio

Por tanto un general mandó

Un escuadrón tras ellos

Para sonar la alarma si realmente lo fueran

Pero ahí en el horizonte había solo 99 globos

(El general los consideró una amenaza ya que pensó que era una invasión espacial)

99 Jets de pelea

Cada uno un gran guerrero

Considerándose ellos mismo el capitán Kirk

Había unos grandes fuegos artificiales

Los vecinos no entendían nada

Y se sentían molestos

Así que dispararon al horizonte

A los 99 globos

(Los vecinos pensaron lo mismo y

comenzaron a dispararles pero eran

solamente globos)

99 ministros de guerra

Cerillos y botes de gasolina

Se creían gente inteligente

Oliendo una buena generosidad

Gritando por la guerra y queriendo el poder

Hombre, quién hubiera pensado

Que las cosas tan lejos llegarían

Tan sólo por 99 globos

(Nadie podía creer que unos globos 


\section{Jahre Krieg}

Ließen keinen Platz für Sieger

Kriegsminister gibt's nicht mehr

Und auch keine Düsenflieger

Heute zieh' ich meine Runden

Seh' die Welt in Trümmern liegen

Hab' 'nen Luftballon gefunden

Denk' an dich und lass' ihn fliegen

\section{comenzarían una guerra)}

99 años de guerra

No dejaron lugar para ganadores

No hay más ministros de guerra

Ni tampoco jets de guerra

Hoy hago yo mis rondas

Veo al mundo estar en ruinas

He encontrado un globo

Pienso en ti y lo dejo volar.

(Después de la guerra ahora todo está en

ruinas, sin embargo aún queda un

globo rojo, el cual ella sigue dedicando a su amado)****

No entanto, o conteúdo como um todo foi corretamente reproduzido. Não houve dificuldades maiores nesse sentido. É uma música também fácil de entender quando cantada e a maior parte dos estudantes já conhecia a versão em alemão e também em inglês. Por esse motivo a música pode ser utilizada a partir do nível A2.

Outra música escolhida para o nível A2 foi Dieser Weg, de Xavier Naidoo ${ }^{7}$. Apesar da letra ser algo complicada, a tradução foi realizada com poucos erros, o que demonstra que no geral o texto foi entendido. Também é cantada de forma clara e facilmente compreendida pelos estudantes do experimento. Por essa razão, o trabalho com essa música no nível A2 é bastante válido.

Tradução da letra da música Dieser Weg de Xavier Naidoo:

\footnotetext{
${ }^{7}$ Xavier Naidoo: Telegramm X. 3p 2005.

****Você tem algum tempo pra mim?/Então canto uma música pra você/Dos 99 balões de ar/E seus caminhos pelo horizonte/Você pensa talvez agora em mim?/Então canto uma música para você/Dos 99 balões de ar/E algo assim vem de algo parecido/99 balões de ar/E seus caminhos pelo horizonte/Pensavam que eram OVNI's no espaço/Por isso mandou um general/Um esquadrão logo atrás/Pra soar o alarme, assim que fosse/Mas lá no horizonte/Eram só 99 balões de ar/99 aviões a jato/Cada um era um grande combatente/Se davam por capitão Kirk/Houve uma grande queima de fogos/Os vizinhos não sacaram nada/E logo ficaram irritados/Por isso atiraram no horizonte/Nos 99 balões de ar/99 ministros de guerra/fósforos e galões de gasolina/se davam por pessoas espertas/farejavam o gordo espólio/chamando pela guerra e desejando o poder/cara, quem pensaria/que iria tão longe/por causa de 99 balões de ar/99 anos de guerra/não há espaço para vencedores/não há mais ministros de guerra/e também não há aviões a jato/hoje dou minhas voltas/vejo o mundo em ruínas/encontrei um balão de ar/pensei em você e o deixei voar.

*****Este caminho/Eu ia pela estrada/E a estrada me levou/A música, que você cantou na última noite/Ela toca em mim/Só mais uns passos/E estava com a chave/Da nossa porta/Esse caminho não será fácil/Esse caminho será pedregoso e difícil/Não estará de acordo com muitos/Mas essa vida oferece muito mais/Foi só um relâmpago/Um momento eu estava lá/Depois dei mais alguns passos/E me ficou claro/Essa caminho não será fácil/Esse caminho será pedregoso e difícil/Não estará de acordo com muitos/Mas essa vida oferece muito mais/Alguns te pisam/Alguns te amam/Alguns abrem mão de tudo por você/Alguns te abençoam/Não ice suas velas/Quando o vento rompe o mar.
} 
Dieser Weg

Also ging ich diese Straße lang und die Straße führte zu mir

Das Lied, das du am letzten Abend sangst

Spielte nun in mir

Noch ein paar Schritte

Und dann war ich da mit dem Schlüssel

zu dieser Tür

Dieser Weg wird kein leichter sein

Dieser Weg wird steinig und schwer

Nicht mit vielen wirst du dir einig sein

Doch dieses Leben bietet so viel mehr

Es war nur ein kleiner Augenblick

Einen Moment war ich nicht da

Danach ging ich einen kleinen Schritt

Und dann wurde es mir klar

Dieser Weg wird kein leichter sein

Dieser Weg wird steinig und schwer

Nicht mit vielen wirst du dir einig sein

Doch dieses Leben bietet so viel mehr

Manche treten dich

Manche lieben dich

Manche geben sich für dich auf

Manche segnen dich

Setz dein Segel nicht,

Wenn der Wind das Meer aufbraust

\section{Este camino}

Iba caminando por esta calle larga

y la calle se dirige al mar

la canción que cantaste la última tarde suena ahora en mí

Solo un par de pasos y estaba allí con la llave de esta puerta.

Este camino no será fácil

Este camino será pedregoso y difícil

No con todos estarás de acuerdo

Pero esta vida ofrece mucho más.

Era solo un pequeño momento

un momento no estaba allí

Entonces di un pequeño paso

y así todo me fue claro.

Este camino no será fácil

Este camino será pedregoso y difícil

No con todos estarás de acuerdo

Pero esta vida ofrece mucho más.

Algunos te pisan, algunos te aman

Algunos dan todo por ti, algunos te bendicen

No hices tu vela, cuando el viento esté en tu contra.*****

Ich werde die Welt verändern do Revolverheld também foi traduzida e apresentada em uma turma já adiantada de nível A2. Não há nada de errado para apontar na tradução submetida, mas vale notar que o aluno que a apresentou já estava muito avançado para esse nível. A letra cantada não é tão fácil de entender, pois muitos registros informais e coloquiais são utilizados. Por este motivo muitos recomendam utilizar a música apenas a partir do nível B1.

Tradução da letra da música Ich werd die Welt verändern ${ }^{8}$ do Revolverheld:

\footnotetext{
${ }^{8}$ Revolverheld: Chaostheorie. Sony BMG Music Entertainment 2007.
} 
Ich werd die Welt verändern

Ich kenne diese Tage jetzt seit Jahren

schon zur genüge

Und es ist schon fast als ob ich mich

selber gern bekriege

Ich kann nicht gut allein sein

Und unter Menschen fang ich an

durchzudrehen

Ich kann mir viel zu viele Fragen stellen

Doch kann ich niemals klare Lösungen sehen

Doch irgendwann wird alles das zu

Ende sein

Und ich werd' anfangen mein Leben zu

Feiern

Ich werd' die Welt verändern

Werd' endlich alles besser machen

Werd' anfangen wieder klar zu kommen

Und mal über mich selber lachen

Und ich weiß dass irgendwann aus

Böse auch mal Gut werden kann

Und wenn gar nichts mehr geht, fang

ich einfach wieder von vorne an

Vielleicht muss ich nur die Tage zählen

Mich durch nervig lange Stunden quälen

es ist ganz egal wie lang das noch geht

weil ich weiß wer am Ende noch steht

Ich werde aufhören immer zu verlieren, werde alles Alte ausrangieren

Ich werd' mich nur noch selber kopieren
Conozco esos días,

desde hace años ha sido suficiente

Y parece como si me gustara pelear conmigo mismo

No puedo estar bien solo

Alrededor de personas me empiezo a marear

Me puedo plantear muchas preguntas

Pero casi nunca puedo ver soluciones claras

Pero algún día todo va a terminar

Y voy a empezar a festejar mi vida.

voy a cambiar el mundo

Finalmente voy a hacer todo mejor

Voy a volver a estar bien

de vez en cuando reírme de mí mismo

Y yo sé que algún día

De lo malo a veces pueden ser salir cosas buenas

Y si nada funciona (y si ya no puedo más)

Vuelvo a empezar simplemente desde el principio

Tal vez solo tenga que contar los días

Torturarme aguantando largas horas irritantes

No importa que tanto dure eso

Porque sé quién queda de pie al final

Voy a dejar de perder siempre

Voy a tirar todo lo viejo

Y voy a copiarme solo a mí mismo

******Vou transformar o mundo/Eu conheço esses dias há anos/Já o suficiente/E é como se eu gostasse de guerrear/Comigo mesmo/Não posso ficar bem sozinho/E entre as pessoas/Começo a ficar atordoado/Posso me fazer muitos questionamentos/Ainda assim não vejo respostas claras/Mas em algum 
Como um exemplo negativo para o nível deve ser citada a música Eisbär ${ }^{9}$ da banda Grauzone, que uma aluna do nível A2 escolheu.

Tradução da música Eisbär da banda Grauzone:

\begin{tabular}{|l|l|}
\hline Eisbär & Oso polar, oso polar, \\
Eisbär, Eisbär, & Hielo frío, hielo frío. \\
kaltes Eis, kaltes Eis, & Oso polar, oso polar, \\
Eisbär, Eisbär, & Hielo frío, hielo frío. \\
kaltes Eis, kaltes Eis. & Quisiera ser un oso polar \\
Ich möchte ein Eisbär sein & en el frío polar, \\
im kalten Polar, & entonces no tendría que gritar más, \\
dann müsste ich nicht mehr schreien, & todo estaba muy claro. \\
alles wär so klar. & Quisiera ser un oso polar \\
Ich möchte ein Eisbär sein & en el frío polar, \\
im kalten Polar, & entonces no tendría que gritar más, \\
dann müsste ich nicht mehr schreien, & todo estaba muy claro. \\
alles wär so klar. & Quisiera ser un oso polar \\
Ich möchte ein Eisbär sein & en el frío polar, \\
im kalten Polar, & entonces no tendría que gritar más, \\
dann müsste ich nicht mehr schreien, & todo estaba muy claro. \\
alles wär so klar. & Quisiera ser un oso polar \\
Ich möchte ein Eisbär sein & en el frío polar, \\
im kalten Polar, & entonces no tendría que gritar más, \\
dann müsste ich nicht mehr schreien, & todo estaba muy claro. \\
alles wär so klar. & Los osos polares no deben lloran. \\
Eisbären müssen nie weinen. & Los osos polares no deben lloran. \\
Eisbären müssen nie weinen. & Los osos polares no deben lloran. \\
Eisbären müssen nie weinen. & Los osos polares no deben lloran. $* * * * * *$ \\
Eisbären müssen nie weinen. & \\
\hline
\end{tabular}

momento tudo/Chegará ao fim/E começarei a festejar/A minha vida/Vou transformar o mundo/Vou finalmente fazer muito melhor/Vou começar a me dar bem de novo/E rir de mim mesmo/E eu sei que em algum momento o/Mal pode se tornar bom/E quando nada mais der/Eu começo simplesmente novamente do começo/Talvez precise apenas contar os dias/Me torturar aguentando as irritantes horas/É indiferente quanto tempo mais dure/Pois sei quem no fim vai cair de pé/Vou parar de perder sempre/Irei jogar fora todo o velho/vou copiar somente a mim mesmo.

${ }^{9}$ Grauzone: Eisbär. mital-U 1981.

******* Urso polar/Urso polar, urso polar/Frio gelo, frio gelo/Urso polar/Urso polar/Eu gostaria de ser/Um urso polar/Então eu não precisaria mais gritar/Tudo seria tão claro/Eu gostaria de ser um urso polar/No frio polar/Então não precisaria mais gritar/Tudo seria tão claro/Eu queria ser um urso polar/No frio polar/Então não precisaria mais gritar/Tudo seria tão claro/Ursos polares nunca precisam chorar/Ursos polares nunca precisam chorar/Ursos polares nunca precisam chorar/Ursos polares nunca precisam chorar. 
O texto é bastante repetitivo, o que diminui o nível de dificuldade para uma turma de A2. Para um nível mais iniciante, seria útil. Poderia, talvez, ser adicionada uma atividade em que os estudantes deveriam pesquisar informações sobre o grupo musical e fazer uma interpretação da música.

\section{CRITÉRIOS PARA AVALIAÇÃO}

$\mathrm{Na}$ avaliação de uma tradução o professor deve se certificar de que todas as informações do conteúdo foram reproduzidas.

\footnotetext{
Se a pergunta sobre a qualidade de uma tradução é respondida dizendo que ela precisa estar "correta", então isso requer uma perspectiva mais acadêmica. Os critérios para isso são a integridade e precisão de uma tradução, uma vez que ela é aplicada especialmente para atividades de tradução no ensino de línguas estrangeiras, caso em que se trata da essencialmente da transmissão de conteúdos básicos (SCHIPPEL, 2006. p.31).
}

Outro critério na avaliação é o grau de compreensão da tradução (SCHIPPEL, 2006, p.31). Além disso, deve ser considerado se em termos de conteúdo a tradução foi apropriada. Erros de gramática e ortografia serão avaliados negativamente apenas se mudarem o sentido das proposições. "A avaliação deve-se referir ao nível do conteúdo" (DE FLORIO HANSEN, 2008, p.5). Deve-se ter consciência de que os estudantes não são tradutores profissionais, assim, não se pode esperar trabalhos profissionais. $\mathrm{O}$ objetivo é muito mais que os alunos trabalhem profundamente com o texto e possam registrar sua aprendizagem. Assim, a avaliação deve se dar no nível de que a tarefa de tradução tenha sido cumprida, mostrando que os estudantes podem traduzir uma letra de música para um amigo e que este poderá entendê-la facilmente.

\section{CONCLUSÃO}

Pudemos observar que, pelo fato de os estudantes terem podido escolher as músicas segundo o seu gosto, ficaram afetivamente mais envolvidos com a tarefa, o que resultou um maior interesse pela atividade. Além disso, trata-se de uma tarefa real, que poderia acontecer ou já aconteceu com participantes do curso. A tarefa possibilita trabalhar profundamente com o texto e o vocabulário, assim como praticar estruturas gramaticais. Ao ouvir-se a música a capacidade de audição também é desenvolvida. Os estudantes podem levar suas próprias preferências à aula e enriquecer uns aos outros, 
assim como ao próprio professor, em relação aos diferentes tipos e gêneros musicais. A tarefa também pode incentivar os estudantes a se ocuparem com músicas em alemão fora da sala de aula e as utilizarem como meio de aprendizagem.

Deve-se enfatizar novamente que a utilização de músicas nas aulas de alemão é uma boa alternativa para os métodos tradicionais de ensino. O objetivo deste artigo está longe de estabelecer a utilização de músicas como meio padrão de ensino, estas ainda devem ser exceções ao longo de um curso. É recomendável a variedade no planejamento das aulas, que devem refletir a heterogeneidade dos próprios alunos. Além disso, é fundamentalmente importante que as tarefas de tradução de letras de música sejam organizadas e adequadas ao objetivo geral, temática, conteúdo gramatical das unidades do curso.

\section{REFERÊNCIAS:}

ECKART, Altenmüller. Macht Musik den Menschen besser?. In: GEO, 11, 68. 2003

DE CARVALO NETO, Geraldo Luiz. Übersetzungübungen im DaF-Unterricht: Mittel zur Überbrückung sprachlicher Schwierigkeiten. In: DaF Brücke 7. 2005, p. 34-35.

DE FLORIO-HANSEN, Inez. Sprachmitteln. Überlegungen zur Mediation im Fremdspracheunterricht. In: PRAXIS Fremdspracheunterricht 5. 2008, p. 3-8.

DRAESNER, Ulrike: „Fremdheit erscheinen zu lassen ist eine Chance und die Kunst von Überseztungen “. Disponível em: <<http://www.goethe.de/ins/cz/prj/lit/buc/ueb/de

3566470.htm >>.

Goethe-Institut Brüssel. (Pop-)Musik im DaF-Unterricht. Disponível em:

<<http://www.goethe.de/mmo/priv/4361501-STANDARD.pdf. >> HALLET, Wolfgang. Kulturelles Lernen. In: HALLET, Wolfgang; KÖNIGS, Frank G. (Ed.). Handbuch Fremdschprachedidaktik. Berlin: Klett; Kallmayer, p. 129-132, 2010.

HAß, Frank. Methoden Fremdspracheunterricht. In: HALLET, Wolfgang; KÖNIGS, Frank G. (Ed.). Handbuch Fremsprachendidaktik. Berlin: Klett, Kallmeyer, p. 151-167, 2010.

KEIM, Lucrecia: Übersetzen im DaF-Unterricht. In: Info-DaF 30, 4. p. 383-394, 2003.

KÖNIGS, Frank G. Sprachmittlung. In: Hallet, Wolfgang; Königs, Frank G. (Ed.). Handbuch Fremdsprachendidaktik. Berlin:Klett; Kallmeyer, p. 96-100, 2010.

NORD, Christiane. Funktionsgerechtigkeit und Loyalität. Therie, Methode und Didaktik des funktionalen Übersetzens. Berlin: Frank \& Timme, 2011. 
REIß, Katharina; VEERMER, Hans J. Grundlegung einer allgemeinen Translationstherie. Tübingen: Niemeyer, 1984.

SCHIPPEL, Larisa. Übersetzungsqualität: Kritik - Kriterien - Bewertungshandeln. Berlin: Frank \& Timme, 2006.

TRIM, John; NORTH, Brian; COSTE, Daniel. Gemeinsamer europäischer Referenzrahmen für Sprachen: lernen lehren, beurteilen. Berlin: Langenscheidt, 2001.

WICKE, Rainer E; ROTTMAN, Karin: Musik und Kunst im Unterricht Deutsch als Fremdsprache. Berlin: Cornelsen, 2013. 